\title{
Situating Sexual Harassment in the Broader Context of Interpersonal Violence: Research, Theory and Policy Implications
}

\author{
Margaret S. Stockdale and Joel T. Nadler
}

\begin{abstract}
Although sexual harassment has been discussed as a form of interpersonal violence, little research has systematically examined both the empirical and theoretical links between sexual harassment and interpersonal violence. We review survey research data that establishes sexual harassment as a form of revictimization from earlier instances of interpersonal violence, such as child sexual abuse and intimate partner violence as well as ways that sexual harassment and interpersonal violence can mutually co-occur, such as from dissolved workplace romances or as an escalation from one form of violence to another. Bronfrenbrenner's $(1977,1979)$ and Grauerholz's (2000) ecological frameworks for understanding interpersonal violence and revictimization from several levels of analysis are invoked to understand the many ways that sexual harassment and interpersonal violence are linked. We further discuss organizational theories of sexual harassment (Fitzgerald, Drasgow, Hulin, Gelfand, \& Magley, 1997) and Routine Activities Theory (Cohen \& Felson, 1979) as frameworks for guiding research in these areas. The review pays particular attention to surveys of multiple forms of sexual victimization, including sexual harassment, documented by the U.S. Military as well as the Military's efforts to comprehensively address these problems.
\end{abstract}

Opinions expressed in this report are those of the authors and should not be construed to represent the official position of DEOMI, the U.S. military services, or the Department of Defense. 
In the opening scenes of the movie North Country, which is based loosely on the case of Lois Jenson versus Eveleth Taconite Company (1993), Josie, the heroine, is laying on her kitchen floor apparently having been beaten by her husband. ${ }^{17}$ Soon after, as a single mother, she seeks employment at the local mine, which promises the best wages and benefits in the area. After she is hired, Josie and her female colleagues endure a barrage of egregious sexual harassment by male coworkers and supervisors. The case depicts the first sexual harassment class action suit. These scenes clarify that Josie is vulnerable and is seeking escape from one form of abuse only to be trapped into another - workplace sexual harassment, and it touches a chord that resonates with many women and men: violence against women is pervasive and has many manifestations. This paper examines the theory and research to support linkages between sexual harassment and other forms of interpersonal violence.

Sexual harassment has been considered to be a part of the continuum of violence against women since it was recognized (Cleveland \& McNamera, 1996; Koss, Goodman, Browne, Fitzgerald, Keita, \& Russo, 1994; MacKinnon, 1979), yet there has been little attempt to examine the associations between sexual harassment and other forms of violence, such as child sexual abuse, stalking, and adult sexual assault or to thoroughly review the links between sexual harassment and other forms of interpersonal violence. Understanding the possible connection between sexual harassment and other forms of sexual violence can directly impact policy in the form of organizational practices, therapeutic treatment, and legal doctrine. Our aim is also to inform research, intervention and policy initiatives by articulating descriptive and theoretical frameworks from which to advance our understanding of the spectrum of sexual violence that includes sexual harassment. After reviewing the evidence of empirical linkages between sexual harassment and other forms of interpersonal violence, we examine the theoretical arguments and perspectives that may account for relationships among these forms of violence. In so doing, we raise a number of cautions in interpreting such linkages, including "blame-the-victim" arguments and attributions of emotional damages to past history of abuse instead of to current claims of victimization. Finally, we examine psychological, organizational, legal and broader policyrelated approaches to addressing interpersonal violence and its connections to sexual harassment.

\section{Definitions and Framework}

To begin this review, we lay out working definitions of sexual harassment and interpersonal violence and present a framework for organizing the various ways that these forms of violence can be associated. Definition of many of these forms of violence may differ for research, therapy, activism or legal and litigation purposes. Legal definitions of sexual harassment vary by state and jurisdiction. Elements of the legal definition typically include unwanted sexual advances, requests for sexual favors (quid pro quo), and any other verbal or physical sexualized conduct resulting in a situation where cooperation is used to determine employment-related decisions or unreasonably interfere with a person's performance including the creation of a hostile work environment (U.S. Equal Employment Opportunity Commission, 1980). The most well-known "psychological definition" is described by Fitzgerald, Swan, and Magley (1997) as a three-part definition consisting of gender harassment ("verbal behavior,

\footnotetext{
${ }^{17}$ In the $8^{\text {th }}$ Circuit Court opinion there is a reference to report by a Special Master appointed to consider the compensatory and punitive damage claims in which a history of domestic violence is experienced by at least one of the plaintiffs, Jenson et al., v. Eveleth Taconite, 130 F.3d 1287 at 1290 (1997).
} 
physical acts, and symbolic gestures that are not aimed at sexual cooperation but that convey insulting, hostile, and degrading attitudes about women," Fitzgerald, Swan, et al., p. 10); unwanted sexual attention, such as unwanted, offensive looks, comments, telephone calls, emails of a sexual nature; and sexual coercion ("extortion of sexual cooperation in return for jobrelated considerations," Fitzgerald, Swan et al., p. 11). Other research has subdivided the category of gender harassment into lewd comments, negative remarks about men, and enforcing the male gender role (Waldo, Berdahl \& Fitzgerald, 1998) or has distinguished between sexist hostility and sexual hostility (Fitzgerald, Magley, Drasgow \& Waldo, 1999).

Interpersonal violence has been referred to by many names, some of which reflect some form of demographic criteria, such as child abuse (i.e., defined by the age of the victims and sometimes the age difference between the victim and perpetrator), or behavioral criteria, such as rape or stalking (defined by specific acts); whereas other labels reflect attempts to capture broad constructs, such as interpersonal violence or intimate partner violence. There are also labels that may still appear in the literature such as domestic violence or wife abuse that have been replaced with contemporary terms. Researchers at the World Health Organization categorized interpersonal violence into two specific forms: family/partner and community, where each is further classified by the type of target (Krug, Mercy, Dahlberg \& Zwi, 2002). Targets of family/partner interpersonal violence may be a child, partner or elder. Targets of community interpersonal violence may be an acquaintance or stranger. The act(s) of violence involve the use of threatened or actual physical force or power and may result in injury, death, psychological harm, maldevelopment or deprivation (Krug, et al., 2002).

Family/partner interpersonal violence may be further classified as child sexual abuse (CSA) or intimate partner violence. Child sexual abuse has been found to be a consistent problem across cultures and historical periods and affects children from all social levels (Walker, Bonner, \& Kaufman, 1988). Pereda, Guilera, Forns, and Gomez-Benito (2009) conducted a meta-analysis of sixty-five studies examining childhood sexual abuse and found that classifications fluctuated on definition and age. Definitions ranged from non-contact abuse such as exhibitionism and sexual requests to non-penetrative contact such as fondling to physical sexual assault (Senn, Carey, \& Vanable, 2008). Additionally, the age used to define childhood varies within different jurisdictions within the United States and varies from study to study and country to country. Age discrepancy has also been suggested as a criterion for defining child sex abuse (Senn, et al., 2008). Both legal and academic definitions of childhood sexual abuse make distinctions between childhood abuse and adolescent sexual assault. Finkelhor (1979) defined childhood sexual abuse as any sexual experiences involving children 12 or under with an individual 5 or more years older or involving an adolescent 13 to 16 years old with an adult 10 or more year older.

Intimate partner violence is defined by the Centers for Disease Control and Prevention as "physical, sexual, or psychological harm by a current or former partner or spouse [that can] occur among heterosexual or same-sex couples and does not require sexual intimacy" (Centers for Disease Control, nd, paragraph 1). Intimate partner violence may also involve physical violence, threats of physical or sexual violence and psychological/emotional violence in addition to sexual violence. Community interpersonal violence, sometimes referred to as adult sexual abuse (ASA) is often defined as sexual assault and can include coerced sexual contact and 
attempted and completed rape (Bachar \& Koss, 2001). Sexual assault legal definitions vary by jurisdiction but typically feature elements including nonconsensual sexual contact, the use of force or threat of bodily harm, or sexual contact with someone unable to provide consent (Testa \& Dermen, 1999).

Sexual harassment meets the definitional criteria of interpersonal violence (IPV). Sexual harassment involves the use of power in one or more of its many manifestations and commonly results in various forms of harm, including psychological harm, such as depression, somatic complaints and posttraumatic stress disorder (PTSD) (Fitzgerald, Drasgow, Hulin, Gelfand \& Magley, 1997; Lim \& Cortina, 2005; Schneider, Swan, \& Fitzgerald, 1997; Stockdale, Logan \& Weston, 2009). Sexual harassment may also result in economic deprivation through the withholding of job-related benefits for lack of sexual cooperation (i.e., quid pro quo sexual harassment) or by the common consequence of turnover or constructive discharge for targets of sexual harassment (Fitzgerald et al, 1997). For the sake of this paper, we separate the various forms of IPV from sexual harassment.

Sexual harassment (SH) and other forms of IPV are theoretically linked by common underlying factors including overarching conditions, such as imbalance of power and patriarchy, as well as individual-level perpetrator characteristics, such as misogynist attitudes. SH and IPV are also empirically linked and it these empirical linkages that we explore, elucidate and explain in this paper. As we will demonstrate, these linkages exist at different levels of analysis. First, targets of IPV are also likely to be targets of SH (co-victimization and revictimization). Second, perpetrators who commit IPV may also be more likely than others to also perpetrate SH (coperpetration). Third, organizational cultures can facilitate or inhibit incidents of both SH and IPV. Although we touch on each of these levels of analyses, the existing literature contains more data on co-victimization and revictimization than on co-perpetration or organizational culture, thus our review more heavily leans on the former. We also recognize the possibility that individuals may differ in their propensity to report experiences of IPV and SH (sensitivity), but we examine and dismiss this perspective in the discussion on victim-blaming cautions below.

\section{Cautions in interpreting co-victimization and revictimization linkages}

There is a risk that the research on victim-centered explanations can be interpreted as victim blaming. Finkelhor and Browne (1985) posited in their traumagenic model of revictimization that child abuse survivors develop poor risk perception capabilities and thus may not properly evaluate situations in which abuse is likely to re-occur. It is tempting, therefore, to presume that in the sexual harassment context, individuals with abuse histories may either be overly sensitive to innocuous workplace social-sexual behaviors, such as an appearance compliment. It also seems plausible that abuse survivors may be less sensitive than others to potentially sexually harassing cues and therefore may "allow" such behavior to escalate. Elements of a legal claim of sexual harassment hinge, among other things, on the complainant's ability to demonstrate that the conduct under inspection was subjectively severe and unwelcome (Meritor Savings Bank v. Vinson, 1986). The actions that the complainant took to indicate unwelcomeness and evidence of its impact on the complainant's well-being are used as evidence to assert or challenge these claims. To the extent that trauma produced from previous interpersonal violence renders a person incapable of distinguishing among and reacting 
appropriately to an array of social-sexual workplace behaviors that ranges from innocuous to severe may undermine her or his credibility.

The empirical research on this issue, however, has not supported this view. Hyper- or hypo-sensitivity to sexually harassing cues as a function of past trauma or its sequalae (e.g., PTSD) may be demonstrated by correlations (positive or negative) between past trauma severity and reactions to sexually harassing stimuli. Stockdale, O'Connor, Gutek and Geer (2002) reviewed the extant literature reporting associations between measures of past interpersonal violence, including sexual harassment, child sexual abuse and adult sexual abuse, and perceptions of sexual harassment, attitudes toward sexual harassment, acknowledgement of sexual harassment, responses to sexual harassment or related measures. Correlations across the 15 studies reviewed ranged from -.17 to .40 , with most correlations being .00 . In their own research examining five different samples of students and working adults who rated perceptions of sexual harassment from a fact-based scenario of sexual harassment, there were no significant associations between self-reports of prior interpersonal violence (e.g., prior sexual harassment) and ratings of the harassment depicted in the scenario. In Stockdale and colleagues' two-panel study of women who had recently received protection orders (Stockdale et al., 2010), no significant associations were found between the severity of any form of interpersonal violence reported in the baseline interview and perceptions of sexual harassment depicted in a scenario rated in the follow-up interview. Also, Fitzgerald, Buchanan, Collinsworth, Magley and Ramos (1999, study 1), provided compelling evidence that abuse survivors' affective reactions to sexually harassing stimuli are no more or less severe than individuals without abuse histories. A sample of 307 college women, 35\% of whom had histories of unwanted sexual touching as a child or adolescent by an older adult, twice viewed four videotaped scenarios of sexual harassment that escalated in severity (the first was a control). There were no significant differences between the abused and non-abused women on their affective reactions to the scenarios, including measures of dysphoria (anxiety and depression) and anger. There were also no significant differences between the groups on measures of how they would have responded to the events depicted in the scenarios if it happened to them. Finally, there was no significant difference between abused and non-abused women on a general measure of attitudes toward sexual harassment.

A related argument may also be made that abuse survivors, as a result of their abuse, develop personality disorders or other forms of psychopathology that disrupt their ability to react appropriately to workplace social-sexual behavior or which fully account for any damages that a formerly abused sexual harassment plaintiff may claim flows from the workplace harassment. Logically, the evidence presented above showing that abuse survivors react no differently to sexual harassment than non-abused individuals precludes the need to test for psychopathology; nonetheless such hypotheses have been examined empirically. Fitzgerald et al. (1999, study 2) conducted in-depth psychological interviews on 56 women involved in sexual harassment litigation, $75 \%$ of whom had a history of some form of prior interpersonal victimization (child sexual or physical abuse and/or adolescent-adult sexual or physical abuse). Although about two thirds of the sample met criteria for a PTSD and/or Major Depressive Disorder diagnosis, there were no differences between previously victimized women and those with no prior history on these diagnoses. There were also no differences between these two groups on personality profiles measured by the Minnesota Multiphasic Personality Inventory (MMPI-2). To counter the 
argument that prior abuse accounts for all the psychological damages that sexual harassment victims may be claiming, Stockdale et al. (2009) found significant associations between sexual harassment experiences and current symptoms of PTSD while controlling for prior abuse or PTSD symptoms that occurred before the harassment ensued (See also Resnick, Kilpatrick, Dansky \& Saunders, 1993). Thus, whereas cognitive dysfunctions and trauma reactions may in part account for revictimization, there appears to be no evidence that abuse survivors are hyperor hypo-sensitive to sexual harassment or that they respond any differently than others to harassing conduct.

\section{Framework for understanding empirical SH and IPV linkages}

In our effort to summarize the research that has examined co-occurrences of sexual harassment with other forms of interpersonal violence (IPV) and to elucidate theoretical frameworks that may explain how sexual harassment and IPV may be linked, we present the classification model shown in Figure 1. This model distinguishes between the temporal relationship between sexual harassment (SH) and IPV - where IPV precedes SH or where IPV and sexual harassment are occurring more or less concurrently - and between the type of IPV perpetrator - an intimate partner or family member versus a community member, such as a stranger or other adult. In the following sections, we elaborate on these categories, review relevant empirical research, and examine theoretical explanations.

\section{IPV that precedes sexual harassment: Revictimization}

Quadrants I and II represent the phenomenon of revictimization which is broadly documented in the IPV literature (Arata, 2002; Breitenbecher, 2001; Classen, Palesh \& Aggarwal, 2005; Messman \& Long, 1996) and largely dominated by intimate partner violence or child sexual abuse as the originating source of trauma (Gidycz, Coble, Lathan \& Layman, 1993; Mayal \& Gold, 1995; Messman-Moore \& Long, 2003). It is estimated that two thirds of individuals who have been sexually victimized experience sexual revictimization (Classen et al., 2005; Sorenson, Stein, Siegel, Golding \& Burnam, 1987). Experiencing child abuse, both sexual and physical, particularly heightens the risk for sexual revictimization both during childhood and into adulthood (Coid, Petruckevitch, Feder, Chung, Richardson \& Moorey, 2001; Desai, Arias; Thompson \& Basile, 2002; Gidycz, Hanson, \& Layman, 1995; Randall \& Haskell, 1995). The recency of the initial victimization, the degree of its sexual invasiveness, being victimized in adolescence, and being victimized by a family member all heighten the risk of sexual revictimization (Classen et al, 2005; Messman-Moore \& Long, 2000; Roodman \& Clum, 2001).

Most of the revictimization research has measured various forms of adult sexual victimization, such as intimate partner violence or rape, as the form of revictimization with some attention paid to sexual harassment. Rosen and Martin (1998) surveyed 1051 male and 305 female soldiers in combat support or combat service support units in three U.S. Army posts to examine prior history of interpersonal violence and recent experiences of sexual harassment and sexual assault and current assessments of psychological well-being. Although the data were self reported and collected at one time, Rosen and Martin's study demonstrated significant associations between reports of prior victimization and various forms of recent sexual harassment among both male and female soldiers. More specifically, among female soldiers, experiencing physical-emotional abuse as a child predicted experiences of sexual coercion forms 
of sexual harassment and experiencing child sexual assault predicted experiences of gender harassment. Among male soldiers, physical-emotional child abuse predicted gender harassment unwanted sexual attention, and both physical neglect and sexual abuse predicted sexual coercion forms of sexual harassment. Other retrospective self-report studies have also shown significant associations between prior interpersonal violence and sexual harassment (e.g., Campbell, Gleeson, Bybee \& Raja, 2008; Houston \& Hwang, 1996; Wyatt \& Riederle, 1994).

There are a handful of studies where the measurement of initial victimization is conducted in advance of the measurement of re-victimization. Such "prospective" or longitudinal studies increase (but do not guarantee) inferences of causality (eg., Gidycz et al., 1993; Humphrey \& White, 2000). Parks, Kim, Day, Garza and Larkby (2010) examined the relationship between childhood maltreatment and adult violent victimization. Data were gathered from two longitudinal studies regarding pregnant women and substance abuse. The results showed that women who experienced any form of childhood maltreatment were at a higher risk to experience adult violent victimization, even after taking into account the influences of social support, substance abuse, adult household characteristics, and psychological status. We were unable to locate any published longitudinal research on sexual harassment revictimization. Stockdale, Berry and Logan (2010) recently reported the results of a two-wave study of nearly 800 women who were recruited from courtrooms after receiving a protection order against an abusive partner. Participants were interviewed shortly after recruitment with instruments measuring life histories of interpersonal violence, emotional and physical health status and other indices of well-being. A follow-up interview was conducted one year later (94\% follow-up rate), and of the 445 participants who reported work experience in the intervening year, $65.6 \%$ experienced at least one incident of sexual harassment as measured by a modified version of Fitzgerald and colleagues' Sexual Experiences Questionnaire (SEQ) (Fitzgerald, Magley, et al., 1999). Moreover, experiences of child physical abuse and interpersonal violence from either the partner from whom the protection order was granted or from another adult, all measured at time 1, and were positively correlated with SEQ scores measured at time 2. Although the research on sexual harassment revictimization is sparse, there appears to be sufficient evidence to conclude that sexual harassment can occur as revictimization.

\section{Theoretical explanations for revictimization}

Several researchers have proffered theoretical explanations for revictimization. Finkelhor and Browne's (1985) traumagenic model suggests that child sexual assault (CSA) victims (a) develop maladaptive sexual behaviors, such as associations between sex and rewards and punishments, promiscuity, and early onset of consensual sexual relations (traumatic sexualization); (b) have difficulty developing trust and have a heightened sense of betrayal; (c) feel stigmatized by the abuse experiences which leads to low self esteem, or (d) in general feel powerless to escape abuse. All of these pathways potentially increase CSA survivors' risks of further abuse. Other researchers have proposed an ecological framework (Bronfenbrenner, 1977, 1979) for understanding how factors at various levels of analyses impact of sexual violence (Belsky, 1980; Heise, 1998).

Grauerholz (2000) applied an ecological framework to understand revictimization. The ecological model of revictimization situates repeated violence in multi-level framework as a way 
to both recognize the importance of victim characteristics as well as the environmental, relational, and perpetrator factors that attach to sexual revictimization (Grauerholz, 2000; Messman-Moore \& Long, 2003). The broadest level, the macrosystem, reflects the cultural context in which abuse survivors and abusers are embedded (Grauerholz, 2000; Messman-Moore \& Long, 2003), including cultural attitudes toward repeated abuse, such as the tendency to blame the victim, as well as the various social stereotypes of and attitudes toward women (Dunn, 2010). It is well established, for example, that men with a propensity to sexually harass or engage in other forms of sexual victimization possess misogynistic attitudes (e.g., Lee, Gizzerone, \& Ashton, 2003; Pryor, 1987; Pryor, Giedd, \& Williams, 1995).

At the most fundamental level of analysis is ontogenic factors which reflect the life circumstances of CSA and other abuse victims. These includes familial characteristics (e.g., family structure, family cohesion, parenting style), and effects of early abuse on victim's self esteem, self concepts, and other factors related to traumatic sexualization (Finkelhor \& Browne, 1985; see also Logan, Walker, Jordan \& Leukefeld, 2006 for a review).

Microsystem factors are those that characterize the immediate context in which the current abuse occurs. Grauerholz (2000) outlined factors that may increase an abuse survivor's risk of exposure to further violence as well as those that may trigger potential perpetrators from acting aggressively toward such targets. Exposure risk factors included the various psychopathologies that result from early abuse experiences, such as dissociative disorders and traumatic sexualization, low self-esteem and stigmatization, and deviance behaviors such as alcohol abuse. Factors that may increase perpetrator aggressiveness include their perceptions of the target as easy prey, feeling justified to behave aggressively, and perceiving that the target is unable to respond assertively (Grauerholz, 2000). Unfortunately, there is a potential for vicious circularity among exposure risk factors and perpetrator factors: abuse survivors' trauma responses and risky behaviors may be the cues that trigger potential perpetrators' aggressive behavior toward them.

Exo-system factors reflect the broader contexts that influence revictimization through their effects on social structures that facilitate further abuse (Grauerholz, 2000). In particular, abuse survivors may be less likely than others to have economic and educational resources, or other forms of social power that buffer their risk of current abuse. Unfortunately the life trajectories of CSA survivors, for example, result in reduced educational and employment prospects, making them dependent on others for economic well-being (Graurholz, 2000). Their dependency, in turn, may increase the likelihood of further abuse (Jewkes, 2002).

Research that has examined the potential causal pathways between episodes of victimization and revictimization has largely supported elements of the ecological model of sexual abuse revictimization. Abuse survivors who have a history of posttraumatic stress disorder (PTSD), an ontogenic factor, are more vulnerable than others to revictimization (Campbell et al., 2008; Classen et al., 2005; Filpas \& Ullman, 2006; Fortier, DiLillo, MessmanMoore, Peugh, DeNardi \& Gaffey, 2009; Krause, Kaltman, Goodman, \& Dutton, 2008; Messman-Moore \& Long, 2003; Messman-Moore, Brown, \& Koelsch, 2005). PTSD and other forms of mental disorders are commonly associated with interpersonal violence early in life (e.g., child sexual assault; Jumper, 1995). Ontogenic factors associated with the development of adult 
psychopathology among survivors of child sexual assault include low socioeconomic status in the family of origin, family alcohol abuse, and frequency of the childhood abuse experiences (Katerndahl, Burge \& Kellogg, 2005). In their review of the literature on women's victimization, Logan, Walker, Jordan and Leukefeld (2006) reported that sexually victimized women are more likely than others to develop low emotional stability. Low emotional stability, in turn, increases vulnerability to traumatic events which may in part explain revictimization.

At the microsystem level, research indicates that risk-taking behaviors, including alcohol consumption and drug abuse are positively associated with sexual victimization and revictimization (Dowdall, 2007; Testa, Livingston, Vanzile-Tamsen \& Frone, 2003). Logan, Shannon, and Walker (2006) suggest that self-medication (alcohol and drug abuse) may be used to deal with past abuse resulting in greater exposure to higher risk situations for further abuse. Messman-Moore and Brown (2007) found evidence that reduced threat perceptions and poor coping skills are associated with revictimization. Additionally, Messman-Moore and Brown found that women who suffer from revictimization had less positive attitudes regarding dating and had reduced risk perceptions in new situations.

In the sexual harassment context, environments that are high risk for sexual harassment include those that are dominated by men (Dell'Ara, \& Maass, 1999; Fitzgerald, Drasgow, Hulin, Gelfand, \& Magley, 1997), have a masculinized or sexualized work environment (e.g., Gutek, 1985; Maass, Cadinu, Guarnieri, \& Grasselli, 2003), have a working climate that tolerates sexual harassment (Hulin, Fitzgerald \& Drasgow, 1996), or in other ways puts abuse survivors in contact with people who have a propensity to sexually harass (e.g., Pryor, LaVite, \& Stoller, 1993; DeCoster, Estes, \& Mueller, 1999). To our knowledge, however, no research has examined whether abuse survivors are more likely than others to find themselves in these types of work environments or whether they are at higher risk for sexual harassment compared to those not previously abused who work in similar situations. Later in this paper, however, we examine features of work environments that may be associated with experiences of multiple forms of interpersonal violence.

As outlined above, early childhood interpersonal violence may disrupt cognitive information processing. Miller, Handley, Markman and Miller (2010) tested the importance of cognitive processes in predicting self-blame after sexual assault. They reasoned that if abuse survivors could easily call to mind ways they could have prevented an assault they would be more likely to engage in self-blame. Miller et al. (2010) interviewed 149 women who had experienced sexual assault and found that those who had been sexually victimized were more likely than others to engage in self-blame as measured by the ease with which they could produce counter-factual examples of ways they could have avoided harm.

Reduced or inaccurate threat perception and poor copings skills have been advanced as a possible explanation that links ontogenic and microsystem factors to revictimization (MessmanMoore \& Long, 2003). In particular, recent research has shown that abuse survivors sometimes develop maladaptive coping strategies, such as avoidance and withdrawal, as a means of suppressing negative emotions that are associated with potentially abusive situations (Fortier, et al., 2009). These coping strategies, in turn, can exacerbate trauma disorders, such as posttraumatic stress disorder (PTSD). PTSD can interfere with functional risk perception and 
ability to protect oneself from harm. Fortier et al. (2009) found significant paths between the severity of CSA, avoidant coping, PTSD, and adult victimization in a three-university sample of undergraduate women who had a history of CSA (see also Golding, 1999). In their two-wave longitudinal study of sexual harassment revictimization, Stockdale et al. (2010) examined the extent to which PTSD symptoms measured in their baseline interview mediated relations between baseline reports of interpersonal violence and follow-up reports of workplace sexual harassment. PTSD was found to mediate associations between child sexual abuse, child physical abuse and interpersonal violence in adulthood and sexual harassment.

\section{Co-Victimization: Sexual Harassment that is Concurrent with other Interpersonal Violence}

Quadrants III and IV in Figure 1 examine sexual harassment that occurs concurrently with other forms of interpersonal victimization. We use the term "concurrently" because the timing of multiple victimization experiences is not typically precisely measured. Instead, mostly cross-sectional survey research measuring experiences of many forms of interpersonal violence, including sexual harassment is reviewed in this section. Therefore it is difficult to distinguish whether sexual harassment is occurring at nearly the same time that other forms of interpersonal violence is occurring or whether there is a temporal difference in the occurrence of these forms of violence and, if so, what that order may be. A recent, comprehensive survey of sexual assault in the military indicated that of the $4.4 \%$ of women who experienced sexual assault (labeled unwanted sexual contact in the survey), $25 \%$ reported being sexual harassed or stalked by the same offender (Rock, Lipari, Cook \& Hale, 2011). Of the total number of assaulted women, $23 \%$ indicated being sexually harassed or stalked before the sexual assault incident and $7 \%$ indicated being harassed or stalked after the incident and $25 \%$ stated that the harassment or stalking occurred both before and after the sexual assault. These data indicate that sexual harassment and other forms of sexual violence do co-occur but that temporal sequences among events may vary. Below we examine the features that might be associated with multiple victimization.

\section{Workplace romance-based victimization}

Quadrant III of Figure 1 represents incidences of intimate partner violence as well as sexual harassment. Although some of the survey research reviewed below has documented cooccurrences of intimate partner violence and sexual harassment (Campbell et al., 2008), the form that we focus on here is harassment that follows dissolved workplace romances. We discuss sexual harassment that results from a dissolved workplace romance in this paper because it is possible that the abuse may cross the boundaries between the workplace and away from the workplace (e.g., the home) due to the nature of the relationship between the parties. Therefore the abuse could be classified as intimate partner violence as well as sexual harassment or it may escalate from one form of violence to the next.

A workplace romance is a consensual relationship between two individuals employed within the organization which can include both emotional and physical attraction (Clarke, 2006). These relationships fall within one or more of the following structural categories: (a) lateral or peer romances; (b) hierarchical romances where one partner holds a higher position in the organization than the other partner (e.g., supervisor-subordinate); and (c) a relationship between 
employees that was established before employment, such as a married couple working in the same organization (which may be either lateral or hierarchical) (Lickey, Berry \& Whelen-Berry, 2009). Surveys by the Society for Human Resource Management (SHRM) indicate that between $19 \%$ and $26 \%$ of human resource professionals indicate that sexual harassment claims that result from the dissolution of a workplace romance have been filed in their organizations (SHRM, $1998 ; 2002 ; 2006)$. The nature of the sexual harassment or interpersonal violence that may occur as a result of the workplace romance dissolution varies as a function of the nature of the relationship (Pierce \& Aguinis, 2001). A hierarchical workplace romance that may have had a utilitarian motive, for example, is more likely than other types of relationships to lead to quid pro quo forms of sexual harassment. A peer-to-peer romance may see the spillover of behaviors, such as standing in close proximity, that were at one point of the relationship perceived as romantic and desirable are now viewed as unwanted sexual attention and thus constitute a hostile work environment (Pierce \& Aguinis, 2001).

Organizational policy makers have demonstrated ambiguity in their stances on workplace romances and their judgments of sexual harassment that follow a dissolved workplace romance. First, very few organizations ( $12 \%$ according to one study) have policies related to workplace romances (Cole, 2009). Second, organizational members who are in a position to judge the veracity of a sexual harassment claim are less likely to find the claim to have violated their sexual harassment policy if the harassment flowed from a dissolved workplace romance than harassment claims that were not connected to a prior romance (Pierce \& Aguinis, 2005; Pierce, Aguinis \& Adams; 2000; Pierce, Broberg, McClure \& Aguinis, 2004). Third, sexual harassment perpetrators are judged as less culpable if the harassment stemmed from a dissolved workplace romance than if it did not (Elkins \& Velez-Castrillon, 2008). Finally, organizations' reluctance to recognize sexual harassment that results from dissolved workplace romances may be due to a widespread belief that policies on workplace romances impinge on privacy issues and that despite the possible risk of sexual harassment, there are documented benefits to workplace romances, such as increased organizational commitment, work motivation, job involvement and job satisfaction (Pierce 1998), let alone benefits related to establishing a long-term romantic relationship (Boyd, 2010).

To date, we have not located theoretical or empirical research that connects dissolved workplace romance-based sexual harassment to other forms of interpersonal violence (IPV), such as stalking or intimate partner violence. Although such a link cannot be assumed to exist without empirical support, the linkages seem logical and the void in both research and organizational awareness on these possible connections is potentially important. For example, IPV that occurs away from the workplace that involves employees involved in a (dissolved) workplace romance may not be noticed by organizational officials and is likely to be outside the purview of organizational policies. Yet such abuse may spillover in the workplace or it may spill from the workplace to other domains. Greater awareness of interpersonal violence that emanates from a dissolved workplace romance on the part of employers and their agents as well as by the courts, law enforcement and social service agencies will help to de-compartmentalize these potentially overlapping forms of IPV so that effective action can be taken to intervene or prevent such abuse in any domain in which it is experienced or witnessed. 


\section{Concurrent sexual harassment and IPV: The special case of the military}

In Quadrant IV of Figure 1, research showing associations between various forms of interpersonal violence and sexual harassment in cross-sectional survey studies is reviewed. Most, but not all, of this research has been conducted in military or military-related settings (e.g., military service academies) or with such populations. Large-scale survey research has been made possible because of heightened awareness of sexual abuse in the military and the structural features of military or military-related settings, such as the ability to reach a samples of activeduty military personnel stationed in various locations or samples of veterans through VA hospitals. Furthermore, the U.S. Military's willingness to fund large-scale research on these matters has helped facilitate this research.

Reliable sources of information about multiple victimization are surveys conducted by the Department of Defense on active-duty military personnel (e.g., Rock et al., 2011). The surveys focus primarily on estimating incidents of sexual assault, which in these surveys is termed unwanted sexual contact, ${ }^{18}$ but information on the extent to which sexual harassment (and stalking) co-occurred with the sexual assault is also gathered.

The 2010 survey of active duty military personnel (Rock et al., 2011) consisted of a probability sample of 90,391 women and men who had at least six months of service at the time of the survey. Sample estimates were weighted to reflect population levels. As reported above, $4.4 \%$ of active duty female military personnel indicated experiencing unwanted sexual contact in the 2010 survey, compared to $6.8 \%$ reported in the 2006 survey. The 2010 rates were highest in the Marine Corp (6.6\%) and lowest in the Air Force (2.3\%) The rates for men experiencing unwanted sexual contact were $0.9 \%$ in 2010 and $1.8 \%$ in 2006. The 2010 rates were also highest in the Marine Corp (1.2\%) and lowest in the Air Force (0.5\%). Of the $4.4 \%$ of women experiencing unwanted sexual contact (sexual assault), 54\% indicated that they had also been sexually harassed ${ }^{19}$ by the perpetrator either before or after the assault incident. Of assaulted men, 38\% also experienced concurrent sexual harassment. Bostock and Daley (2007) analyzed a probability sample of active duty U.S. Air Force women and found that $31.8 \%$ of rape victims, $29.5 \%$ of victims experiencing other forms of sexual assault, and $33.3 \%$ of attempted sexual assault victims also reported sexual harassment from a boss. Similarly, 26.7\%, 20.1\%, and $25.6 \%$ of victims of rape, other sexual assault and attempted sexual assault, respectively, also experienced sexual harassment from a coworker.

Surveys of veterans seeking services from VA hospitals also indicate that incidents of sexual assault tend to also co-occur with sexual harassment. Harned, Ormerod, Palmieri, Collinsworth, and Read (2002) examined survey data of over twenty thousand women in all branches of the military and found that $4.2 \%$ reported incidents of sexual assault and 72.4 reported incidents of sexual harassment in the twelve months preceding the survey. Moreover, $99.7 \%$ of those reporting sexual assault had also experienced sexual harassment. In a national

\footnotetext{
${ }^{18}$ Defined as "uninvited and unwelcome completed or attempted sexual intercourse, sodomy (oral or anal sex), penetration by a finger or object, and the unwanted touching of genitalia and other sexually related areas of the body" (Rock, et al. 2011(b), p. 1; Cook \& Lipari, 2011, p. iii)

${ }^{19}$ Stalking is also included in these estimates, but most incidents (91\%) were sexual harassment or a combination of sexual harassment and stalking.
} 
sample of women veterans who had served in Vietnam, post-Vietnam and Persian Gulf eras $(n=558)$, Sadler, Booth, Cook and Doebbeling (2003) indicated that $70 \%$ reported sexual harassment during military service; $54 \%$ reported unwanted sexual contact; $30 \%$ reported completed or attempted rapes. Among military rape survivors, the perpetrator was often identified as someone who had sexually harassed them (48.2\%).

Although clinical samples of veterans receiving treatment from VA hospitals may logically report higher rates of sexual assault than those not receiving treatment, the patterns of co-occurrence of assault with sexual harassment are similar as the more representative probability samples of active duty military or veterans. Skinner, Kressin, Frayne, Tripp, Hankin, Miller and Sullivan (2000) surveyed over 3600 women veterans sampled from VA hospital records and found rates of sexual assault at $23 \%$ and sexual harassment at $55 \%$. Similar to the Harned et al. (2002) study, however, Skinner et al. also found that almost all of the women in their sample who had experienced sexual assault had also experienced sexual harassment (98\%). Suris, Lind, Kashner and Borman (2007) measured various forms of sexual assault among a sample of women veterans receiving outpatient treatment at a single VA center. Their survey measured experiences of sexual harassment and various forms of sexual assault that had occurred as a child, as a civilian adult or as an adult on active duty in the military. Unfortunately they did not report specific statistics on what percent of their sample experienced more than one type of sexual assault or co-occurrences of sexual harassment and sexual assault, within or across participants' life periods, but they did indicate that multiple victimization was common.

We located two studies that conducted surveys of random samples of veterans utilizing VA services or filing some form of VA disability claim(s). Thus the samples are clinical, but representative of such populations. In a fairly small but random sample of female veterans who had utilized services at an urban VA $(n=268)$, Campbell et al. (2008) identified four clusters of women on the basis of their experiences of various forms of interpersonal violence, including child sexual assault, adult sexual assault, intimate partner violence and sexual harassment. Cluster I (36\%) was composed of women who scored low on all forms of sexual violence. Women in cluster II (16\%), had experienced the highest rates of child sexual assault, adult sexual assault and sexual harassment combined; they were also the second most likely to experience intimate partner violence as well. Cluster III (22\%) was composed of women who had fairly high rates of child sexual assault, adult sexual assault and sexual harassment, with slightly lower levels of intimate partner violence; and cluster IV (26\%) were women who tended to experience intimate partner violence and sexual harassment. Altogether, $74 \%$ of the sample had experienced at least one form of sexual violence, and at least $32 \%$ had experienced two or more forms. In a larger random sample of men and women veterans who filed disability claims for PTSD $(n=3,337)$, Murdoch, Polusny, Hodges and Cowper (2006) reported correlations of .58 for women and .42 for men between in-service sexual harassment and in-service sexual assault. Correlations between in-service sexual harassment and post-service sexual assault were .23 for women and .22 for men.

\section{Theoretical explanations for co-victimization}

Sexual harassment and other forms of interpersonal violence share many underlying causal or precipitating linkages, therefore co-victimization is not surprising. Returning to an 
ecological framework for understanding multiple victimization (Bronfenbrenner, 1979), at the macro-level, cultures that normalize sexual violence, sustain power differences between men and women, and encourage victim-blaming belief systems foster many forms of sexual violence, including sexual harassment (Cleveland \& Kerst, 1993; Dunn, 2010; Grauerholz, 2000; \& Kilmartin \& Allison, 2007). Sheffield (2007) suggested that a societal combination of dominance and sexuality along with victim blaming results an environment that desensitizes violence against women. Studies have found support for this theory in both workplace and military populations (Fain \& Andertin, 1987; Harned et al., 2002). At the individual level of analysis, research has found heightened propensities to sexually harass among men who automatically link sexual cues with power cues (Bargh, Raymond, Pryor, \& Strack, 1995) suggesting that there may be common underlying factors connected to power that explain the propensity engage in sexual harassment and the propensity to engage in other forms of interpersonal violence.

Focusing more closely at the micro-system, researchers have identified organizational risk factors for workplace sexual harassment. Fitzgerald and her colleagues articulated an integrative model to explain the occurrence and effects of sexual harassment (Fitzgerald, Gelfand, and Drasgow, 1995; Fitzgerald, Drasgow, Hulin, Gelfand \& Magley, 1997; Fitzgerald, Magley et al., 1999). They identified organizational climate for tolerating sexual harassment and masculine job-gender context as the key organizational factors that facilitate sexual harassment. Specifically, climates where employees perceive that leaders do not take complaints or concerns about sexual harassment seriously, where complainants are not likely to be believed, and where perpetrators are not adequately punished have been positively linked to high rates of sexual harassment (Harned, 2002; Fitzgerald, et al., 1997). Additionally, incidents of sexual harassment increase in job contexts where men significantly outnumber women, where a woman is one of the first women to occupy a particular job area, and where the attributes of the job or job environment are masculinized or sexualized (Harned, 2002; Fitzgerald et al., 1997; Gutek, 1985; Sadler et al., 2003).

Military environments supply many of the necessary ingredients to cultivate multiple forms of sexual abuse. Almost all military occupational specialties are male dominated and masculinized; although women have always served in the military, their integration into a broader variety of roles is relatively recent, thus many women in the military are gender pioneers; and until recently many military climates could be described as being tolerant of sexual misconduct and sexual harassment (Fitzgerald, Drasgow, et al., 1999). In addition, the boundaries between work and non-work are often blurred in military settings, especially in deployment conditions. Thus, what may begin as sexual harassment while on duty may spillover to adult sexual abuse in off-duty periods. Other environments that contain many of these ingredients are those where there is a predominance of men and where working (or studying) and living quarters are close: protective services (policing and firefighting), off-shore drilling sites, mines and mining towns, and traditionally male colleges and universities, such as military services academies, to name a few.

General theories of crime offer frameworks for understanding how certain work environments may foster sexual harassment either concurrently with other forms of IPV or as a form of revictimization. The claim of Routine Activities Theory (Cohen \& Felson, 1979; 
Mannon, 1997) is that incidents of crime are predicted by the confluence of motivated offenders, vulnerable victims, and the lack of capable guardians. What makes a potential offender motivated is being in close proximity to potential targets and having the opportunity to get away with the offense, which can happen in environments where the likelihood of punishment is low and with targets who may not be able to effectively resist.

Routine Activities Theory may provide both a viable framework for understanding why sexual harassment and other forms of IPV may occur either concurrently or as revictimization, and it may point to effective ways to shape interventions. As outlined below, survivors of interpersonal violence may have less-effective coping strategies to deal effectively with sexually harassing overtures. Also, such individuals may be more likely than others to find themselves in environments that are high-risk for sexual harassment, such as low-wage jobs in firms that offer little protection against sexual harassment. Moreover, these environments may permit sexual harassment to fester, which may attract individuals with a propensity to sexually harass. Thus, individuals with IPV histories may find themselves in situations where they are both exposed to motivated offenders and unprotected by capable guardians in the form of sound sexual harassment policies carried out by responsible management. Routine Activities Theory, therefore, has the potential for identifying (and hopefully eradicating) those conditions that lead to the "perfect storm" for revictimization and co-victimization: vulnerable victims, motivated offenders, and incapable guardians. We expand on this analysis below.

Sexual harassment occurs most often in male-dominated work environments (potential motivated offenders) that have lax policies on sexual harassment or complacent leadership (lack of capable guardians) (Gruber, 1998). Individuals who have a history of prior sexual abuse are clearly vulnerable victims for workplace sexual harassment (Fitzgerald et al., 1997). Further research is needed to understand why this is so. As noted above, individuals with abuse histories appear to be neither hypersensitive to innocuous cues, nor do they appear to be more psychologically disturbed than sexual harassment targets without abuse histories. But, they are more vulnerable to sexual harassment.

Most research on revictimization has studied the behaviors or psychological status of the victim, noting that PTSD symptomology and ineffective coping strategies may heighten their vulnerability (e.g., Fortier et al., 2009), but looking more closely at motivated offenders may be enlightening. In particular, do potential harassers seek out women who appear to have abuse histories with the thought that they might be "damaged goods" or "easy prey" who will not be able to easily resist harassment? Finally, capable guardians, in the form of trained, responsible and supportive supervisors and coworkers, cohesive work groups, effective policies that outline clear admonition against sexual harassment and procedures for effectively investigating and punishing offenders have been found to positively reduce sexual harassment incidents (Goldberg, 2007; 2011; Offermann \& Malamut, 2002; Rosen \& Martin, 1997; Settles, Cortina, Malley \& Stewart, 2006; Stockdale \& Sagrestano, 2010).

However, we know of only a few organizations where their training programs, policies and intervention programs calls attention to the confluence of sexual harassment with other forms of IPV. One is in the private sector (Verizon) and the other in the public sector (U.S. Military). The U.S. military, despite or perhaps because of their history of high rates of multiple 
forms of sexual victimization, has taken considerable steps in recent years to address this problem. We review and critique those efforts with an eye toward identifying best practices for organizational approaches to addressing sexual victimization.

\section{Policies, Practices and Interventions}

The quadrants depicted in Figure 1 roughly classify the various empirical linkages between interpersonal violence and sexual harassment and therefore provide guidance for policies, practices and interventions that may be implemented by various actors in the ecological network in which interpersonal violence and sexual harassment are embedded. In quadrants I and II (revictimization), attention should be paid to developing effective interventions at the ontogenic level to forestall the onset of damaging developmental and other psychological disruptions that left untreated may lead to re-victimization. At the microsystem level, interventions may focus on identifying those "motivated offenders" who may be likely to target individuals who have histories of prior abuse. This may include adding modules to workplace sexual harassment training programs that debunk myths about abuse survivors as well as raise awareness of their vulnerabilities. At the exo-system level, vocational training programs that prepare displaced workers (and others) for new occupations could include programs on sexual harassment awareness and how to utilize complaint procedures properly.

For quadrants III and IV (co-victimization), firms should first recognize that interpersonal violence and dissolved workplace romances do affect their businesses including the likelihood of spillover to sexual harassment. Second, they should recognize that their own cultures or other characteristics of their organizations may foster multiple forms of sexualized victimization, especially if those cultures are highly male-dominated or otherwise masculinized and if there are permeable boundaries between work and non-work environments. We expand on organizational interventions and models below.

A recent review of the relatively scant literature on organizational approaches to sexual harassment concluded that sexual harassment policies should:

(1) Assert strong disapproval for harassing conduct; (2) clearly define sexual harassment and provide a range of examples; (3) explain sanctions that reflect the severity of conduct; (4) provide procedures for prompt and equitable grievances of sexual harassment; (5) prohibit retaliation against the complainant or his or her witnesses; (6) explain how individuals may obtain legal recourse and direct interested parties to the appropriate state or federal agencies; and (7) be widely and regularly disseminated (Stockdale \& Sagrestano, 2010, p. 227).

Policies, however, are only as good as the procedures that back them up and the practices in place to train organizational members how to both respond effectively to incidents of potential sexual harassment and to prevent harassment from occurring. In this article, we have sought to broaden our understanding of the risk factors for sexual harassment by addressing its associations with other forms of interpersonal violence. Sexual harassment training, therefore, should address sexual harassment as a revictimization risk, as a spillover risk or risk-factor for other forms interpersonal violence. Furthermore, such training should debunk myths that sexual harassment complainants who have either in the past or who are currently experiencing other 
forms of sexual victimization are less worthy of care and protection than other complainants. We examine some innovative organizational programs and strategies that have been developed to address multiple forms of sexual violence.

Some private-sector organizations have recognized how domestic and workplace violence may interact and influence workplace performance (Pollack, Austin, \& Grisso, 2010). Verizon communications is an example of a company that has implemented employee assistance programs (EAP) aimed at intimate partner violence (Bowman \& Rich, 2005). EAP programs often include resources, support, and work leave options for victims of domestic and workplace violence. Another leader in integrating support with training and prevention is the U.S. Military.

In 2005, the U.S. Military established perhaps one of the most comprehensive organizational approaches to combating sexual violence, called the Sexual Assault Prevention and Response (SAPR) program (Department of Defense, 2011), and they have invested considerable resources in this program since 2007. The SAPR program has developed and implemented a number of strategic initiatives to address five priority areas designed to: (a) institutionalize prevention strategies in the military community; (b) increase the climate of victim confidence associated with reporting; (c) improve sexual assault response; (d) improve system accountability; and (e) improve stakeholder knowledge and understanding of sexual assault prevention and response (SAPR) (Department of Defense, 2011, p. 6).

Among the innovative strategies to increase assault victims' reporting is a two-pronged reporting system. The first is a traditional "unrestricted" reporting system in which the alleged perpetrator(s) is identified and a formal investigation ensues. The second system, labeled "restricted reporting" permits assault victims to anonymously seek access to medical care and other forms of advocacy services without triggering an official investigation. In monitoring the effectiveness of these and other strategies in the SAPR program, the Department of Defense (2011) noted that $71 \%$ of women and $85 \%$ of men surveyed indicated experiencing an assault in the context of military duty in the past year did not utilize either the unrestricted or restricted reporting system. Primary reasons for not reporting assaults included not wanting others to know, feeling uncomfortable making a report or believing that the report would not be kept confidential. Therefore, the SAPR program implemented a number of steps to help reduce the stigma of reporting sexual assaults. These include a public service campaign, training programs for investigators and attorneys on the risks of revictimization by the military justice system, and using social networking tools to support conversations about sexual assault. Other elements of the SAPR program include a helpline within the DoD, outreach programs for civilian programs that partner with the military to provide services to assault victims, a training program for responders, and continuous training programs of military personnel including special training programs for commanders that emphasize their responsibility to intervene when they have reason to believe that an assault did or may soon occur.

Surveys conducted in even-numbered years by the Defense Manpower Data Center provide evidence of the effectiveness of SAPR initiatives. Between 2006 and 2010, incidents of sexual assault in the military have dropped from $6.8 \%$ to $4.4 \%$ for women and from $1.8 \%$ to $0.9 \%$ from men (Rock et al., 2011). In addition, a strong majority of respondents in the 2010 survey (over $88 \%$ ) indicate a positive climate toward filing a report of sexual assault without fear 
of reprisal; over $90 \%$ stated that they had participated in SAPR-related training and of those over $85 \%$ indicated that the training was moderately to very effective in preventing or reducing sexual assault (Rock et al., 2011). The Department of Defense (2011) recognizes, however, that problems of sexual assault in the military have not disappeared and that further vigilance is needed. Nonetheless, their multi-pronged and multi-layered approach seems to be paying positive dividends.

The SAPR program distinguishes between sexual assault and sexual harassment. SAPR and the DOD's survey program refers to sexual assault as unwanted sexual contact which "includes rape, non-consensual sodomy (oral or anal sex), or indecent assault (unwanted, inappropriate sexual contact or fondling) and can occur regardless of gender, age, or spousal relationship" (Lipari, Cook, Rock \& Matos, 2008, p iv). The SAPR Office (SAPRO) implements and monitors programs and policies with regard to unwanted sexual contact (sexual assault). Sexual harassment in the U.S. military, on the other hand, falls under the purview of the Office of the Secretary of Defense Office of Diversity Management and Equal Opportunity. Sexual harassment includes "crude and offensive behavior, unwanted attention, and sexual coercion" (Lipari et al., 2008, p. vii); and along with sexist behavior comprises unwanted genderrelated experiences. Familial sex crimes (crimes against children and family members) are the purview of the Office of the Secretary of Defense Family Advocacy Program. A component of training programs offered by SAPRO is to help military personnel distinguish between sexual assault and sexual harassment.

Although the DoD's survey program monitors experiences of both unwanted sexual contact and sexual harassment, the fact that sexual harassment is carved out of SAPRO's purview may warrant reconsideration given that both empirical evidence and theory links various forms of sexual assault and sexual harassment - especially evidence from military surveys showing that a high percentage of sexual assault victims were either sexually harassed or stalked by their perpetrators before the assault incident (Harned et al., 2002; Sadler et al., 2003). For example, SAPRO initiatives that could be broadened to include considerations of sexual harassment are the restricted and unrestricted reporting options and training to military personnel to be vigilant of sexual harassment as a precursor to more serious forms of sexual harassment. Military personnel at all levels would also benefit from understanding the links between prior victimization, such as child sexual assault, and revictimization in the form of sexual harassment as well as adult sexual assault. Commanders and other leaders could be trained to recognize signs of co-victimization or revictimization such as avoidance coping, or risky behavior such as heavy drinking and refer individuals to appropriate services. Leaders should also take appropriate measures to modify the conditions that exacerbate any form of victimization as well as repeat victimization. These include monitoring the environment for sexually derogatory stimuli including graffiti and banter that mock vulnerable populations such as abuse survivors. Leaders should also clarify and support the paths to resources that targets should follow to receive appropriate relief. Such resources should be cognizant of the connections between all forms of interpersonal violence including sexual harassment. All ranks of military personnel should also be trained to understand and recognize the links between interpersonal violence and sexual harassment and be taught how to intervene appropriately when they believe that assaults or harassment have occurred or are likely to occur. 
These recommendations are not limited to the U.S. Military. Sexual harassment training programs in all contexts should include a discussion of the links between sexual harassment and other forms of interpersonal violence. This discussion should note the links between prior sexual abuse and sexual harassment revictimization as well as concurrent risks of sexual harassment with interpersonal violence, especially in the context of dissolved workplace romances or in work environments where the boundaries between work and nonwork are fluid. In addition to adding training elements to discuss linkages between sexual harassment and other forms of interpersonal violence, organizations may follow the lead of SAPRO to provide or refer employees to services that may help them deal effectively with intimate partner violence or with the consequences of past abuse. Increasing employees' mastery over these matters is likely to translate to effective means of confronting potential sexual harassment or other forms of abuse in the workplace (Pearlin \& Schooler, 1978).

Litigation practices should also be carefully examined with eye toward discerning the difference between plausible and unsupported connections between sexual harassment, interpersonal violence and the various problems that result from sexual abuse in the past. A tactic used by defense attorneys to mitigate the amount of damages potentially awarded to sexual harassment plaintiffs is to argue that a plaintiff who claims more than garden-variety psychological effects from harassment may not be eligible for compensation if she or he has a prior history of sexual abuse. It is the effects of the prior abuse and not the sexual harassment that is the cause of psychological effects, such as major depression or PTSD, so the argument goes. Prominent defense attorney James McDonald, who specializes in mental health issues in the workplace and author of Mental and Emotional Injuries in Employment Litigation (McDonald \& Kulick, 2001), argues this point: claims of mental health damages by sexual harassment plaintiffs with a history of prior sexual abuse are not the result of sexual harassment but instead from the prior abuse (McDonald, 2007; McDonald \& Feldman-Schorrig, 1994). Similarly, special masters, who are assigned by courts to sort out case-by-case claims in multi-plaintiff cases, such as class action suits, may also rely on this type of faulty reasoning to exclude particular plaintiffs from receiving their full share of compensatory damages.

This appeared to be the case in the first class action sexual harassment lawsuit on which the movie North Country was based. In the appellate case of Jenson et al., v. Eveleth Taconite (1997), the $8^{\text {th }}$ Circuit made reference to a lengthy report by a special master who was appointed to allocate damage awards to Jenson and her fellow class members. The court found that the special master made egregious errors in collecting and over-relying on evidence of prior abuse and prior mental health problems of class members. The justices' stated that the special master minimized the amount of damages to be awarded to class members who had experienced prior abuse or prior mental health problems reasoning that their emotional and physical damages were not due to the harassment experienced at Eveleth Taconite but instead due to the prior abuse.

Empirical research does not support the supposition that only the effects of prior abuse accounts for psychological trauma that flows from sexual harassment such as PTSD or major depression. As noted above, Stockdale et al., (2009) found that sexual harassment was related to the onset of PTSD symptoms after controlling for sexual abuse that occurred in the past, including child sexual abuse and interpersonal partner violence, as well as pre-existing symptoms of PTSD. Nonetheless, prior and concurrent forms of interpersonal violence are 
associated with experiences of sexual harassment. As demonstrated in this paper there is no single explanation these associations. Litigators and the justice system in general should take an informed look at full circumstances surrounding claims of sexual harassment that include prior or concurrent histories of other forms of interpersonal violence.

\section{Conclusions}

Sexual harassment and other forms of interpersonal violence such as childhood sexual abuse and sexual assault are often researched and theorized separately. Because sexual harassment is considered an employment issue and is legally carved out as such, it is often conceptualized outside of the continuum of interpersonal violence and often treated as an unfair work practice, not as a form of violence. The empirical links commonly found in the victimization literatures indicates sexual harassment is not only related to other forms of interpersonal violence, but also firmly positioned in the continuum of violence. Previous abuse not only predicts increased risk for future abuse, but also an increased risk of being the target of sexual harassment.

The sobering statistics of revictimization paints a grim picture of increased risk that spirals with each act of victimization. Initial victimization, especially sexual abuse in childhood and adolescence, is clearly associated with increased risk of future adult sexual victimization including sexual harassment. Empirical longitudinal studies have examined multiple theories to explain this relationship. The strongest support for a potential cause for revictimization is the development of maladaptive coping styles and a decreased sensitivity to early warning signs. The stress and trauma of victimization often leads to risky coping behaviors including substance abuse that further increases the likelihood of future victimization. Additionally, those previously victimized, partly due to risky life behaviors, may also be less sensitive to dangerous situations. Reduced social support and financial insecurity may further limit an individual's ability to avoid or respond to potential future threats. The cycle starts with an initial act of victimization which leads to increased risky behavior thus further reducing personal, financial and social resources and increasing exposure to future threats. This same pattern could easily result in past victims occupying jobs with an increased likelihood of experiencing sexual harassment.

The defining factor between other forms of sexualized violence and sexual harassment is one of context. Sexual harassment from hostile environments to coercive quid pro quo sexual assault occurs within the workplace, a context which carries its own set of laws and legal obligations. Other forms of interpersonal violence usually occur outside of work. This work/non-work divide has contributed to the theoretical and legal separation of sexual harassment from non-workplace sexual abuse

The U.S. military's success with interventions focused on reducing all forms of interpersonal violence including sexual harassment is encouraging. The substantial improvement in reducing reported assaults in the military suggests such programs may be successfully adapted for use in other types of organizations. However, the military has the advantage of targeting programs that affect both work and non-work (family) arenas, which may be beyond many organizations' abilities or legal rights. Organizations need to recognize that an important part of any sexual harassment policy or plan must recognize that harassment lies in a continuum of violence that both exceeds the work boundaries and is affected by employee's non-work life. We 
hope we have provided fodder for future research on the connections between multiple forms of victimization including sexual harassment and for developing sound policies and practices that take this comprehensive approach. 


\section{References}

Arata, C. M. (2002). Child sexual abuse and sexual revictimization. Clinical Psychology: Science and Practice, 9, 135-164.

Bachar, K. \& Koss, M. (2001). Rape. In J. Worell (Ed.), Encyclopedia of women and gender: Sex similarities and differences and the impact of society on gender (Vol. 2) (pp. 893903). San Diego, CA: Academic Press.

Bargh, J. A., Raymond, P. Pryor, J. B., \& Strack, F. (1995). Attractiveness and the underling: An automatic power $\rightarrow$ sex association and its consequences for sexual harassment and aggression. Journal of Personality and Social Psychology, 68, 768-781.

Belskey, J. (1980). Child maltreatment: An ecological integration. American Psychologist, 35, $320-335$.

Bostock, D. J., \& Daley, J. G. (2007). Lifetime and current sexual assault and harassment victimization rates of active-duty United States Air Force women. Violence Against Women, 13, 927-944.

Bowman, C., \& Rich, P. (2005). EAP's domestic violence role: One MBHO/EAP teamed up with a major telecommunications provider to address the problem through the workplace. Behavioral Health Management, 25, 38-41.

Boyd, C. (2010). The debate over the prohibition of romance in the workplace. Journal of Business Ethics, 97, 325-338,

Breitenbecher, K.H. (2001). Sexual revictimization among women: A review of the literature focusing on the empirical investigations. Aggression and Violent Behavior, 6, 415-432.

Breitenbecher, K. H. (2008). The convergent validities of two measures of dating behaviors related to risk for sexual victimization. Journal of Interpersonal Violence, 23(8), 10951107. doi: $10.1177 / 0886260507313974$

Bronfenbrenner, U. (1977). Toward an experimental ecology of human development. American Psychologist, 32, 513-531.

Bronfenbrenner, U. (1979). The ecology of human development. Cambridge, MA: Harvard University Press.

Brownmiller, S. (1975). Against our will: Men, women, and rape. Toronto: Bantam Books.

Campbell, R., Gleeson, M. R., Bybee, D., \& Raja, S. (2008). The co-occurrence of child sexual abuse, adult sexual assault, intimate partner violence, and sexual harassment: A meditational model of posttraumatic stress disorder and physical health outcomes. 
Journal of Consulting and Clinical Psychology, 76, 194-207. doi: 10.1037/002006X.76.2.-194

Centers for Disease Control and Prevention (N.D.). Intimate partner violence: Definitions. Accessed May 20, 2011 at http://www.cdc.gov/ViolencePrevention/intimatepartnerviolence/definitions.html

Clarke, L. (2006). Sexual relationships and sexual conduct in the workplace. Legal Studies, 26, 347-368.

Classen, C. C., Palesh, O. G., \& Aggarwal, R. (2005). Sexual revictimization: A review of the Empirical literature. Trauma, Violence, \& Abuse, 6, 103-129. doi: $10.1177 / 1524838005275087$.

Cleveland, J., \& Kerst, M. (1993). Sexual harassment and perceptions of power: An underarticulated relationship. Journal of Vocational Behavior, 42, 49-67.

Cleveland, J. N., \& McNamara, K. (1996). Understanding sexual harassment: Contributions from research on domestic violence and organizational change. In M. S. Stockdale (Ed.) Sexual harassment in the workplace: Perspectives, frontiers, and response strategies (pp. 217-240). Thousand Oaks, CA: Sage.

Cohen, I. E., \& Felson, M. (1979). Social change and crime rate trends: A routine activity approach. American Sociological Review, 44, 588-608.

Coid, J., Petruckevitch, A., Feder, G., Chung,W., Richardson, J.,\& Moorey, S. (2001). Relation between childhood sexual and physical abuse and risk of revictimisation in women: A cross-sectional survey. Lancet, 358, 450-454.

Cole N. (2009). Workplace romance: A justice analysis. Journal of Business Psychology, 24, 363-372.

De Coster, S., Estes, S. B., \& Mueller, C. W. (1999). Routine activities and sexual harassment in the workplace. Work and Occupations, 26, 21-49.

Dell'A ra, E., \& Maass, A. (1999). Studying sexual harassment in the laboratory: are egalitarian women at higher risk? Sex Roles, 41, 681-704.

Department of Defense (2011). Department of Defense Annual Report on Sexual Assault in the Military: Fiscal Year 2010. Available at http://www.sapr.mil/media/pdf/reports/DoD_Fiscal_Year_2010_Annual_Report_on_Sex ual_Assault_in_the_Military.pdf.

Desai, S., Arias, I., Thompson, M. P., \& Basile, K. C. (2002). Childhood victimization and subsequent adult revictimization assessed in a nationally representative sample of women and men. Violence and Victims, 17, 639-653. 
Dowdall, G. W. (2007). The role of alcohol abuse in college student victimization. In B. S. Fisher \& J. J. Sloan III (Eds.), Campus crime: Legal, social, and policy perspectives (2nd ed., pp. 167-209). Springfield, IL: Charles C. Thomas Publisher.

Dunn, J. L. (2010). Judging victims: Why we stigmatize survivors, and how they reclaim respect. Boulder, CO: Lynne Rienner Publishers.

Elkins, T. J., \& Velez-Castrillon, S. (2008). Victims' and observers' perceptions of sexual harassment: Implications for employers' legal risks in North America. The International Journal of Human Resource Management, 19, 1435-1454.

Fain, T. C., \& Anderton, D. L. (1987). Sexual harassment: Organizational context and diffuse status. Sex Roles, 17, 291-311.

Farley, L. (1978). Sexual shakedown. New York: McGraw-Hill.

Filpas, H. H., \& Ullman, S. E. (2006). Child sexual abuse, coping responses, self-blame, posttraumatic stress disorder, and adult sexual revictimization. Journal of Interpersonal Violence, 21, 652-672. doi: 10.1177/0886260506286879

Finkelhor, D. (1979). Sexually victimized children. New York: The Free Press.

Finkelhor, D., \& Browne, A. (1985). The traumatic impact of child sexual abuse: A conceptualization. American Journal of Orthopsychiatry, 55, 530-541.

Fitzgerald, L. F., Buchanan, N. T., Collinsworth, L. L., Magley, V. J., \& Ramos, A. M. (1999). Junk Logic: The abuse defense in sexual harassment litigation. Psychology, Public Policy, and Law, 5, 730-759.

Fitzgerald, L. F., Drasgow, F., Hulin, C. L., Gelfand, M. J., \& Magley, V. J. (1997). Antecedents and consequences of sexual harassment in organizations: a test of an integrated model. Journal of Applied Psychology, 82, 578-589.

Fitzgerald, L. F., Gelfand, M. J., \& Drasgow, F. (1995). Measuring sexual harassment: Theoretical and psychometric advances. Basic and Applied Social Psychology, 17, 425445.

Fitzgerald, L. F., Drasgow, F., \& Magley, V. J. (1999). Sexual harassment in the armed forces: A test of an integrated model. Military Psychology, 11, 329-343.

Fitzgerald, L. F., Magley, V. J., Drasgow, F., \& Waldo, C. (1999). Measuring sexual harassment in the military: The Sexual Experiences Questionnaire (SEQ-DoD). Military Psychology, 11, 243-263.

Fitzgerald, L. F., Swan, S., Magley, V. J. (1997). But was it really sexual harassment?: Legal, behavioral, and psychological definitions of the workplace victimization of women. In 
W. O'Donohue, (Ed) Sexual harassment: Theory, research, and treatment, pp 5-28. Needham Heights, MA, US: Allyn \& Bacon.

Fortier, M. A., DiLillo, D., Messman-Moore, T. L., Peugh, J., DeNardi, K. A., \& Gaffey, K. J. (2009). Severity of child sexual abuse and revictimization: The mediating role of coping and trauma symptoms. Psychology of Women Quarterly, 33, 308-320. doi: 10.1111/j.1471-6402.2009.01503.x

Gelles, R.J., \& Straus, M. (1988). Intimate violence: The causes and consequences of abuse in the American family. New York: Touchstone.

Gidycz, C. A., Coble, C. N., Latham, L., \& Layman, M. J. (1993). Sexual assault experience in adulthood and prior victimization experiences: a prospective analysis. Psychology of Women Quarterly, 17, 151-168.

Gidycz, C. A., Hanson, K., \& Layman, M. J. (1995). A prospective analysis of the relationships among sexual assault experiences: An extension of previous findings. Psychology of Women Quarterly, 19, 5-29.

Goldberg, C. B. (2007). Impact of training and conflict avoidance on responses to sexual harassment. Psychology of Women Quarterly, 31, 62-72.

Goldberg, C. B. (2011). What do we really know about sexual harassment training effectively? In M. A. Paludi, C. A. Paludi, Jr., \& DeSouza, E. R. (Eds). Praeger handbook on understanding and preventing workplace discrimination (Vols 1 \& 2). Pp. 45-48. Santa Barbara, CA: Praeger.

Golding, J. (1999). Intimate partner violence as a risk factor for mental disorders: A metaanalysis. Journal of Family Violence, 14, 99-132. doi: 10.1023/A:1022079418229

Grauerholz, L. (2000). An ecological approach to understanding sexual revictimization: Linking personal, interpersonal, and sociocultural factors and processes. Child Maltreatment, 5, $5-17$.

Greene, D. M., \& Navarro, R. L. (1998). Situation-specific assertiveness in the epidemiology of sexual victimization among university women. Psychology of Women Quarterly, 22, 589604.

Gruber, J. E. (1998). The impact of male work environments and organizational policies on women's experiences of sexual harassment. Gender \& Society, 12, 301-320.

Gruber, J. E., \& Smith, M. D. (1995). Women's responses to sexual harassment: a multivariate analysis. Basic and Applied Social Psychology, 17, 543-562.

Gutek, B. A., (1985). Sex and the workplace. San Francisco, CA: Jossey-Bass. 
Harned, M., Ormerod, A., Palmieri, P., Collinsworth, L. L., \& Reed, M. (2002). Sexual assault by workplace personnel and other types of sexual harassment: A comparison of antecedents and consequences. Journal of Occupational Health Psychology, 7, 174-188.

Hedtke, K. A., Ruggiero, K. J., Fitzgerald, M. M., Zinzow, H. M., Saunders, B. E., Resnick, H.S., \& Kilpatrick, D. G. (2008). A longitudinal investigation of interpersonal violence in relation to mental health and substance abuse. Journal of Consulting and Clinical Psychology, 76, 633-647.

Heise, L. (1998). Violence against women: An integrated, ecological framework. Violence Against Women, 4, 262-290.

Himelein, M. J. (1995). Risk factors for sexual victimization in dating: A longitudinal study of college women. Psychology of Women Quarterly, 19, 31-48.

Houston, S., \& Hwang, N. (1996). Correlates of the objective and subjective experiences of sexual harassment in high school. Sex Roles, 34, 189-204.

Hulin, C. L., Fitzgerald, L. F., \& Drasgow, F. (1996). Organizational influences on sexual harassment. In M. S. Stockdale (Ed.) Sexual harassment in the workplace: Perspectives, frontiers, and response strategies (pp. 127-150). Thousand Oaks, CA: Sage.

Humphrey, J. A., \& White, J.W. (2000).Women's vulnerability to sexual assault from adolescence to young adulthood. Journal of Adolescent Health, 27, 419-424.

Jenson et al., v. Eveleth Taconite, 130 F.3d 1287 at 1290 (1997).

Jenson v. Eveleth Taconite Company, 824, F. Supp. 847 (1993).

Jewkes, R. (2002). Intimate partner violence. Causes and prevention, The Lancet, 359, 14231429.

Jumper, S. A. (1995). Meta-analysis of the relationship of child sexual abuse to adult psychological adjustment. Child Abuse and Neglect, 19, 715-728.

Katerndahl, D., Burge, S., and Kellogg, N. (2005). Predictors of development of adult psychopathology in female victims of childhood sexual abuse. The Journal of Nervous and Mental Disease, 193, 258-264.

Kilmartin, C., \& Allison, J. (2007). Men's violence against women: Theory, research, and activism. Philadelphia, PA: Lawrence Erlbaum.

Kilpatrick, D. G., Saunders, B. E., Veronen, L. J., Best, C. L., \& Von, J. M. (1987). Criminal victimization: Lifetime prevalence, reporting to police, and psychological impact. Crime and Delinquency, 33, 479-489. 
Koss, M. P., Goodman, L. A., Browne, A., Fitzgerald, L. F., Keita, G. P., \& Russo, N. F. (1994). No safe haven: Male violence against women at home, at work, and in the community. Washington DC: American Psychological Association.

Krause, E. D., Kaltman, S., Goodman, L. A., \& Dutton, M. A. (2008). Avoidant coping and PTSD symptoms related to domestic violence exposure: A longitudinal study. Journal of Traumatic Stress, 21, 83-90. doi: 10.1002/jts.20288

Krug, E. G., Mercy, J. A., Dahlberg, D. L., \& Zwi, A. B. (2002). The world report on violence and health. Lancet, 360, 1083-1088.

Lee, K., Gizzarone, M., \& Ashton, M. C. (2003). Personality and the likelihood to sexually harass. Sex Roles, 49, 59-69. doi: 10.1023/A:1023961603479

Lickey, N. C., Berry, G. R., \& Whelan-Berry, K. S. (2009). Responding to workplace romance: A proactive and pragmatic approach. The Journal of Business Inquiry, 8, 100-119.

Lim, S., \& Cortina, L. M. (2005). Interpersonal mistreatment in the workplace: The interface and impact of general incivility and sexual harassment. Journal of Applied Psychology, 90, 483-496. doi: 10.1037/0021-9010.90.3.483

Lipari, R. N., Cook, P. J., Rock, L. M., \& Matos, K. (2008). 2006 Gender Relations Survey of Active Duty Members. Arlington, VA.:Defense Manpower Data Center. Available at http://www.sapr.mil/media/pdf/research/WGRA_OverviewReport.pdf.

Logan, T. K., Shannon, L., \& Walker, W. (2006). Protective orders in rural and urban areas: A multiple perspective study. Violence Against Women, 11, 876-911. doi: $10.1177 / 1077801205276985$.

Logan, T., Walker, R., Jordan, C., \& Leukefeld, C. (2006). Women and victimization: Contributing factors, interventions, and implications. Washington, DC: American Psychological Association Press.

MacKinnon, C. A. (1979). Sexual harassment of working women. New Haven, CT: Yale University Press

Mannon, J. M. (1997). Domestic and intimate violence: An application of routine activities theory. Aggression and Violent Behavior, 2, 9-24.

Maass, A., Cadinu, M., Guarnieri, G., \& Grasselli, A. (2003). Sexual harassment under social identity threat: The computer harassment paradigm. Journal of Personality and Social Psychology, 85, 853-870.

Mayall, A., \& Gold, S. R. (1995). Definitional issues and mediating variable in the sexual revictimization of women sexual abused as children. Journal of Interpersonal Violence, $10,26-42$. 
McDonald, J. J. Jr. (2007). Emotional distress Damages: Torture or Fair Play? Presentation to the Atlanta Bar Association Meeting. Georgia.

McDonald, J. J. Jr., \& Feldman-Schorrig, S. P. (1994). The relevance of childhood sexual abuse in sexual harassment cases. Employee Relations Law Journal, 20, 221-236.

McDonald, J. J., Jr., \& Kulick F. B. (2001). Mental and emotional injuries in employment litigation $\left(2^{\text {nd }} \mathrm{Ed}\right)$. Washington, D. C.: Bureau of National Affairs.

Meritor Savings Bank v. Vinson, 477 U.S. 57 (1986).

Messman, T. L., \& Long, P. J. (1996). Child sexual abuse and its relationship to revictimization in adult women: A review. Clinical Psychology Review, 16, 397-420.

Messman-Moore, T. L., \& Brown, A. L. (2006). Risk perception, rape, and sexual revictimization: A prospective study of college women. Psychology of Women Quarterly, 30, 159-172.

Messman-Moore, T. L., Brown, A. L., \& Koelsch, L. E. (2005). Posttraumatic symptoms and self-dysfunction as consequences and predictors of sexual revictimization. Journal of Traumatic Stress, 18, 253-261. doi: 10.1002/jts.20023.

Messman-Moore, T. L., \& Long, P. J. (2000). Child sexual abuse and revictimization in the form of adult sexual abuse, adult physical abuse, and adult psychological maltreatment. Journal of Interpersonal violence, 15, 489-502. doi: 10.1177/088626000015005003

Messman-Moore, T. L., \& Long, P. J. (2003). The role of childhood sexual abuse sequelae in the sexual revictimization of women: An empirical review and theoretical reformulation. Clinical Psychology Review, 23, 537-571. doi:10.1016/S0272-7358(02)00203-9.

Miller, A.K., Handley, I.M, Markman, K.D., \& Miller, J.H. 2010. Deconstructing self-blame following sexual assault: The critical roles of cognitive content and process. Violence Against Women. 10, 1120-1137. Doi: 10.1177/1077801210382874.

Murdoch, M., Polusny, M., Hodges, J., \& Cowper, D. (2006). The association between inservice sexual harassment and post-traumatic stress disorder among department of veterans affairs disability applicants. Military Medicine, 171, 166-173.

Offermann, L. R., \& Malamut, A. B. (2002). When leaders harass: The impact of target perceptions of organizational leadership and climate on harassment reporting and outcomes. Journal of Applied Psychology, 87, 885-893. DOI: 10.1037//00219010.87.5.885

Parks, S.E., Kim, K.H., Day, N.L., Garza, M.A., and Larkby, C.A. (2010). Lifetime self-reported victimization among low-income, urban women: The relationship between childhood 
maltreatment and adult violent victimization. Journal of Interpersonal Violence, 26, 1111-1128. DOI: 10. 1177/0886260510368158.

Pearlin, L., \& Schooler, C. (1978). The structure of coping. Journal of Health and Social Behavior, 19, 2-21, doi: 10.2307/2136319.

Pereda, N., Guilera, G., Forns, M., \& Gomez-Benito, J. (2009). The prevalence of child sexual abuse in communities and student samples: A meta-analysis. Clinical Psychology Review, $29,328-338$.

Pierce, C. A. (1998). Factors associated with participating in romantic relationships in a work environment. Journal of Applied Social Psychology, 28, 1712-1730.

Pierce, C. A., \& Aguinis, H. (2001). A framework for investigating the link between workplace romance and sexual harassment. Group \& Organizational Management, 26, 206-229.

Pierce, C. A., \& Aguinis, H. (2005). Legal standards, ethical standards, and responses to socialsexual conduct at work. Journal of Organizational Behavior, 26, 727-732.

Pierce, C. A., Aguinis, H., \& Adams, S. K. (2000). Effects of a dissolved workplace romance and rater characteristics of responses to a sexual harassment accusation. Academy of Management Journal, 43, 869-880.

Pierce, C. A., Broberg, B. J., McClure, J. R., \& Aguinis, H. (2004). Responding to sexual harassment complaints: Effects of a dissolved workplace romance on decision-making standards. Organizational Behavior and Human Decision Processes, 95, 66-82.

Pollack, K. M., Austin, W., \& Grisso, J. A. (2010). Employee assistance programs: A workplace resource to address intimate partner violence. Journal of Women's Health, 19, 729-733.

Pryor, J. B. (1987). Sexual harassment proclivities in men. Sex Roles, 17, 269-290.

Pryor, J. B., Giedd, J. L. \& Williams, K. B. (1995). A social psychological model for predicting sexual harassment. Journal of Social Issues, 51, 69-84.

Pryor, J. B., LaVite, C. M., \& Stoller, L. M. (1993). A social-psychological analysis of sexual harassment: The person/situation interaction. Journal of Vocational Behavior, 42, 68-83.

Randall, M., \& Haskell, L. (1995). Sexual violence in women's lives: Findings from the Women's Safety Project, a community-based survey. Violence Against Women, 1, 6-31.

Resnick, H. S., Kilpatrick, D. G., Dansky, B. S., \& Saunders, B. E. (1993). Prevalence of civilian trauma and posttraumatic stress disorder in a representative national sample of women. Journal of Consulting and Clinical Psychology, 61, 984-991.

Rock, L M., Lipari, R. N., Cook, P. J., \& Hale, A. D. (2011). 2010 Workplace and Gender Relations Survey of Active Duty Members: Overview Report on Sexual Assault. Arlington, VA: Defense Manpower Data Center. Available at: 
http://www.sapr.mil/media/pdf/research/DMDC_2010_WGRA_Overview_Report_of_Se xual_Assault.pdf.

Roodman, A., \& Clum, G. (2001). Revictimization rates and method variance: A meta-analysis. Clinical Psychology Review, 21, 183-204.

Rosen, L., \& Martin, L. (1997). Sexual harassment, cohesion, and combat readiness in U.S. Army support units. Armed Forces \& Society, 24, 221-244.

Rosen, L., \& Martin, L. (1998). Childhood maltreatment history as a risk factor for sexual harassment among US Army soldiers. Violence and Victims, 13(3), 269-286.

Sadler, A. G., Booth, B. M., Cook, B. L., Doebbeling, B. D. (2003). Factors associated with women's risk of rape in the military environment. American Journal of Industrial Medicine, 43, 262-273.

Schneider, K. T., Swan, S., \& Fitzgerald, L. F. (1997). Job-related and psychological effects of sexual harassment in the workplace: Empirical evidence from two organizations. Journal of Applied Psychology, 82, 401-415,

Senn, T. E., Carey, M. P., \& Vanable, P. A. (2008). Childhood and adolescent sexual abuse and subsequent sexual risk behavior: Evidence from controlled studies, methodological critique, and suggestions for research. Clinical Psychology Review, 28, 711-735.

Settles, I. H., Cortina, L. M., Malley, J., \& Stewart, A. J. (2006). The climate for women in academic science: The good, the bad, and the changeable. Psychology of Women Quarterly, 30, 47-58.

Sheffield, C. J. (2007). Sexual terrorism. In L. L. O’Toole, J. R. Schiffman, \& M. L. Kiter Edwards (Eds.), Gender violence: Interdisciplinary perspectives ( $2^{\text {nd }}$ ed.) (pp. 111-130). New York: New York University Press.

Skinner, K. M., Kressin, N. Frayne, S., Tripp, T. J., Hankin, C. S., Miler, D. R., \& Sullivan, L. M. (2000). The prevalence of military sexual assault among female veterans' administration outpatients. Journal of Interpersonal Violence, 15, 291-310. Doi: 10.1177/022626000015003005.

SHRM (Society for Human Resources Management). (1998). Workplace romance survey. Alexandria, VA: SHRM.

SHRM (Society for Human Resources Management). (2002). Workplace romance survey. Alexandria, VA: SHRM.

SHRM (Society for Human Resources Management). (2006). Workplace romance survey. Alexandria, VA: SHRM. 
Sorenson, S. B., Stein, J. A., Siegel, J. M., Golding, J. M., \& Burnam, M. A. (1987). The prevalence of adult sexual assault: The Los Angeles Epidemiologic Catchment Area Project. American Journal of Epidemiology, 126, 1154-1164.

Stockdale, M.S., Berry, S. \& Logan, TK., (2010). An Empirical, Prospective Investigation of Revictimization and Sexual Harassment. In. C.L.Z. Dubois (chair), "Sexual Harassment: Some New Perspectives on an Old Problem," symposium presented at the Society for Industrial Organizational Psychology Annual Conference. April, 2010, Atlanta.

Stockdale, M.S., Logan, T.K., \& Weston, R. (2009). Sexual harassment and posttraumatic stress disorder: Damages beyond prior abuse. Law Human Behavior. 33, 405-418. Doi: 10.1007/s10979-008-9162-8.

Stockdale, M. S., O`Connor, M., Gutek, B. A., \& Geer, T. M. (2002). The relationship between prior sexual abuse and reactions to sexual harassment: Literature review and empirical study. Psychology, Public Policy and the Law, 8, 64-95.

Stockdale, M. S., \& Sagrestano, L. M. (2010). Resources for Victims of Sexual Harassment, in M. A. Paludi, \& F. L. Denmark (Eds). Victims of Sexual Assault and Abuse: Resources and Responses for Individuals and Families. (Vol 2: Cultural, Community, Educational and Advocacy Responses), pp. 211-239. Santa Barbara, CA: Praeger.

Suris, A., Lind, L., Kashner, M., \& Borman, P. D. (2007). Mental health, quality of life, and health functioning in women veterans: Differential outcomes associated with military and civilian sexual assault. Journal of Interpersonal Violence, 22, 179-197. DOI: $10.1177 / 0886260506295347$.

Testa, M., \& Dermen, K. (1999). The differential correlates of sexual coercion and rape. Journal of Interpersonal Violence, 14, 548-561.

Testa, M., Livingston, J., Vanzile-Tamsen, C., \& Frone, M. R. (2003). The role of women's substance use in vulnerability to forcible and incapacitated rape. Journal of Studies on Alcohol, 64, 756-764.

U.S. Equal Employment Opportunity Commission. (1980). Discrimination because of sex under Title VII of the 1964 Civil Rights Act as amended: Adoption of interim guidelines Sexual harassment. Federal Register, 45, 25024-25025.

Waldo, C. R., Berdahl, J. L., \& Fitzgerald, L. F. (1998). Are men sexually harassed? If so, by whom? Law and Human Behavior, 22, 55-79.

Walker, C. E., Bonner, B. L., \& Kaufman, K. L. (1988). The physically and sexually abused child. Evaluation and treatment. London, G.B.: Pergamon Press.

Wyatt, G. E., Lawrence, J., Vodounon, A., \& Mickey, M. R. (1992). The Wyatt Sex History Questionnaire: A structured interview for female sexual history taking. Journal of Child Sexual Abuse, 1, 51-68. 
Wyatt, G. E., \& Riederle, M. (1995). The prevalence and context of sexual harassment among African American and White American women. Journal of Interpersonal Violence, 10, 309-321. 


\section{Appendix}

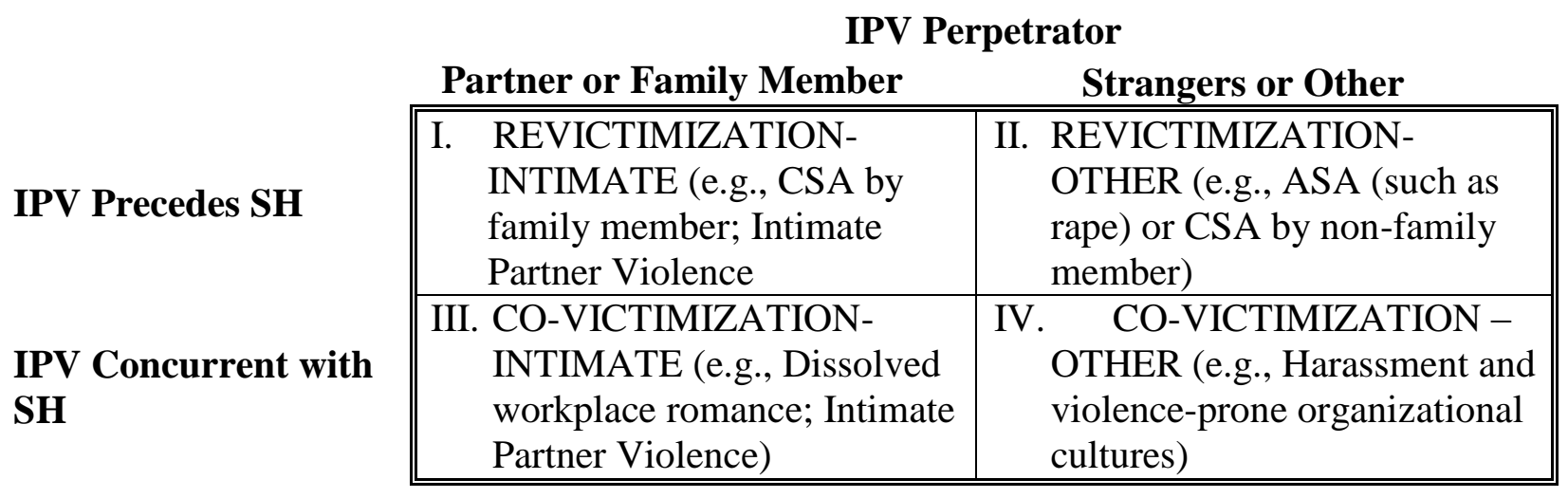

Figure 1. Framework for classifying structural relationships between IPV and Sexual Harassment (SH)

Note: IPV=Interpersonal Violence; $\mathrm{SH}=$ Sexual Harassment; CSA=Child Sexual Assault; ASA=Adult Sexual Assault. 
